\title{
Posição sistemática de quatro espécies de Cyrtoneurina Giglio-Tos (Diptera, Muscidae)
}

\author{
Márcia Souto Couri ${ }^{1,2}$ \\ Denise Medeiros Pamplona ${ }^{1}$
}

\begin{abstract}
Systematic position of four species of Cyrtoneurina Giglio-Tos (Diptera, Muscidae). The systematic position of four species considered as Cyrtoneurina in Carvalho et al. (1993) - C. alifusca Couri, 1982; C. brunnea (Hough, 1900); C. pallipes Stein, 1918 and C. scutellata Johnson, 1919 are discussed. These species were originally described, respectively, in Cyrtoneurina, Muscina, Cyrtoneurina and Clinopera. The detailed analysis of the morphology, especially of the terminalia, enabled the transference of C. brunnea and C. pallipes to Cyrtoneuropsis and C. scutellata to Neomuscina, all are new combinations, and the confirmation of C. alifusca in the Cyrtoneurina. The morphology of the terminalia is described and illustrated. The lectotype of Cyrtoneuropsis pallipes (Stein, 1918) is herein proposed. KEY WORDS. Diptera, Muscidae, Cyrtoneurina, lectotype, taxonomy
\end{abstract}

O gênero Cyrtoneurina Giglio-Tos, 1893 foi dividido recentemente por PAMPLONA (1999) em dois gêneros: Cyrtoneurina com sete espécies e Paracyrtoneurina com 31 espécies. PONT \& PAMPLONA (no prelo) corrigiram o nome deste último para Cyrtoneuropsis Malloch, 1925.

As quatro espécies estudadas - C. alifusca Couri, 1982; C. brunnea (Hough, 1900); C. pallipes Stein, 1918 and C. scutellata Johnson, 1919, não foram incluídas em nenhum destes dois gêneros e PAMPLONA (1999) informou que as posições sistemáticas das mesmas estavam sendo revistas, em função principalmente das análises do material-tipo e do estudo das terminálias. A revisão das posições destas espécies é o objeto central deste estudo.

Cyrtoneuropsis brunnea e C. pallipes são transferidas para Cyrtoneuropsis e $C$. scutellata para Neomuscina, enquanto a posição de C. alifusca foi confirmada entre os Cyrtoneurina.

O material examinado pertence às coleções do (MNRJ) Museu Nacional, Rio de Janeiro, Rio de Janeiro, Brasil; (ZMHU) Museum für Naturkunde, Humboldt-Universität, Berlim, Alemanha e; (MCZC) Museum of Comparative Zoology, Cambridge, Massachusetts, Estados Unidos da América do Norte.

A seguir são apresentadas redescrições das espécies estudadas, ilustrações da terminália e as justificativas para suas novas combinações.

1) Departamento de Entomologia, Museu Nacional, Universidade Federal do Rio de Janeiro. Quinta da Boa Boa Vista, São Cristóvão, 20940-040 Rio de Janeiro, Rio de Janeiro, Brasil.

2) Bolsista de Produtividade em Pesquisa, CNPq. 


\section{Cyrtoneuropsis brunnea (Hough, 1900), comb.n.}

Figs 1-8

Coloração. Abdômen castanho com pouca polinosidade cinza. Frontália, parafaciália, faciália, lúnula e genas amareladas com polinosidade prateada; palpos amarelos; probóscida castanha. Mesotórax com polinosidade uniforme e com listras castanhas um pouco difusas; úmero e ápice do escutelo amarelados. Caliptras acastanhadas com bordas escurecidas. Halter amarelo. Prosterno com cílios amarelos. Pernas amareladas.

Macho. Comprimento: corpo: 6,0mm-7,0mm; asa: 6,0mm-7,0mm.

Cabeça. Olhos afastados por um espaço cerca de 8,5 a 10 vezes menor que a largura da cabeça no nível do ocelo anterior. Cerdas frontais em número de um par no nível da lúnula seguido de cerca de cinco pares de cílios. Antena inserida acima do nível da metade do olho. Flagelo medindo cerca de três a quatro vezes o pedicelo; arista em média com 26 cílios; com cílios dorsais secundários que no terço basal da arista são bem maiores que o seu diâmetro; vibrissa forte, cerca do comprimento da arista palpo com cerca de oito cílios longos na borda.

Tórax. Cerdas dorso-centrais 2:4; cerdas acrosticais 0:1. Duas cerdas póspronotais aproximadamente do mesmo comprimento; cerda pré-alar forte; uma pós-umeral; uma pré-sutural; uma intra-alar; duas supra-alares, a anterior maior; duas pós-supra-alares, a posterior o dobro da anterior; uma intra pós-alar. Notopleura com duas cerdas semelhantes. Escutelo com dois pares de cerdas basais, um par de laterais cerca da metade do par apical, um par de apical; com várias séries de cílios látero-ventrais da base ao ápice. Prosterno ciliado. Propleura nua. Duas cerdas proepisternais, duas cerdas proepimerais. Anepisterno com uma série de cinco cerdas na borda posterior. Catepisterno com pelos de fundo em toda extensão. Anepímero com cilios longos em toda extensão. Catepímero nu. Espiráculo posterior cerca do tamanho do anterior e sem cílios negros na borda inferior. Caliptra inferior medindo cerca de 1,6 a 1,8 vezes a superior. Asa com remígio ciliado, porção apical nua, veia $R_{1}$ não setulosa depois da transversa umeral, veia $M_{1+2}$ próximo ao ápice com uma forte curvatura na direção da $\mathrm{R}_{4+5}$; veia $\mathrm{R}_{4+5}$ com poucos cílios após o nódulo; dm-cu bem sinuosa (Fig. 1). Fêmur anterior, nas faces anterior e ântero-ventral sem cerdas; faces póstero-ventral, posterior e póstero-dorsal com uma série de cerdas. Tíbia anterior nas faces dorsal, póstero-dorsal e póstero-ventral com uma cerda apical. Tarso com pêlos sensitivos longos, maiores na base do primeiro tarsômero. Fêmur médio, na face dorsal com uma cerda pré-apical próxima às das faces posterior e póstero-dorsal. Tíbia média nas faces anterior, ântero-ventral e ventral com duas, uma e uma cerdas apicais respectivamente. Fêmur posterior na face ântero-ventral com três cerdas no terço apical, face ântero-dorsal com uma série de cerdas; face posterior sem cerdas; face póstero-dorsal com uma cerda pré-apical Tíbia posterior na face ântero-ventral com duas ou três cerdas, faces ântero-dorsal e póstero-dorsal com duas cerdas pequenas no terço médio.

Abdômen. Quinto esternito com margem anterior arredondada, margem posterior com densa ciliação e reentrância lateral; superfície dorsal formando ângulo (Fig. 2). 


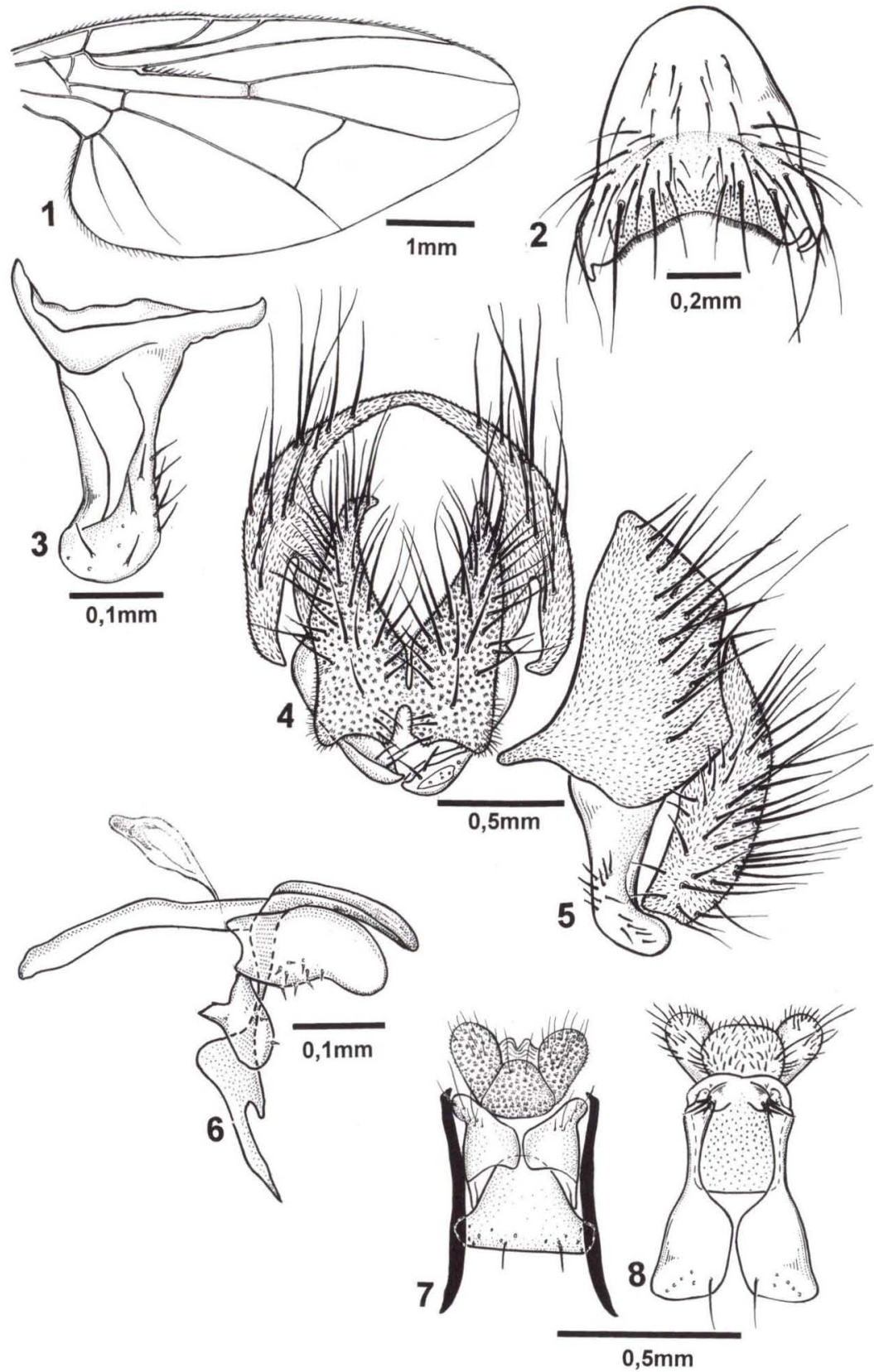

Figs. 1-8. Cyrtoneuropsis brunnea. (1) Asa, vista dorsal; (2) quinto esternito, macho; (3) surstilo; (4) placa cercal, vista dorsal; (5) placa cercal, vista lateral; (6) complexo fálico, vista lateral; (7) ovipositor, vista dorsal; (8) ovipositor, vista ventral. 
Terminália. Surstilo sem ciliação e com cerca de 14 cerdas na metade apical (Fig. 3). Placa cercal com margens laterais e anteriores retas, esta última com reentrância central (Figs 4, 5). Parâmero maior que gonópodo (Fig. 6).

Fêmea. Comprimento do corpo: $6,0 \mathrm{~mm}$. Comprimento da asa: $6,0 \mathrm{~mm}$.

Semelhante ao macho, diferindo no que se segue: olhos com bordas paralelas em direção ao vértice e afastados por um espaço cerca de 2,3 vezes menor que a largura da cabeça. Cerdas frontais em número de três, intercaladas de outras três menores e fracas. Fêmur médio na face ântero-ventral com cílios do mesmo comprimento; faces ântero-dorsal, dorsal e póstero-dorsal, cada uma com uma cerda semelhantes entre si, fortes e inseridas no plano transversal do fêmur. Fêmur posterior, na face ântero-dorsal sem cerda pré-apical.

Terminália. Ovipositor pouco telescopável; epiprocto grande, triangular e ciliado; tergitos e esternitos estreitos e bem esclerotinizados (Figs 7, 8).

Material examinado: BrasiL, Mato Grosso do Sul: Salobra, 1 macho (comparado com o tipo pelo Dr. Dalcy de O. Albuquerque), 31.VIII.1940, Comissão Inst. Oswaldo Cruz leg. (MNRJ); 1 fêmea, IX.1940 (MNRJ); Rio de Janeiro: Maricá, 2 machos, 22-23.III.1957, D. Albuquerque leg. (MNRJ); São Paulo: Barueri, 1 macho, 12.VII.1955, K. Lenko leg. (MNRJ).

Registro geográfico. Brasil e Argentina.

Comentários. Pelo aspecto geral, C. brunnea poderia ser confundida com uma Neomuscina, em especial pela coloração e pela forte curvatura da veia $\mathrm{M}_{1+2}$ em direção a $\mathrm{R}_{4+5}$. Um exame mais acurado, porém, não nos deixa enganar, uma vez que ela apresenta ciliação no remígio, apenas na parte basal, porção apical é nua e o prosterno é setuloso, caracteres que não estão presentes em Neomuscina. Seguindo a conceituação de PAMPLONA (1999), esta espécie foi posicionada entre os Cyrtoneuropsis, pelos caracteres diagnósticos, especialmente os relacionados à terminália, embora ela não apresente ciliação na $\mathrm{R}_{1}$, após a veia transversal umeral. Cyrtoneuropsis brunnea e C. pallipes diferenciam-se de todos os demais Cyrtoneuropsis por apresentarem a veia $\mathrm{R}_{1}$ nua após a transversal umeral e por apresentar curvatura da veia M1+2 como em Neomuscina. Na chave de PAMPLONA (1999), C. brunnea situa-se próximo à $C$. dubia e $C$. pallipes de $C$. immunda. Cyrtoneuropsis brunnea e $C$. pallipes podem ser distintas, respectivamente, pela morfologia da terminália (Figs 2-8, 10-16) e pelos seguintes caracteres: um par de cerdas frontais no nível da lúnula seguido de cerca de cinco pares de cílios, ausência de mancha na veia r-m, presença de pré-alar forte; e, um par de cerdas frontais no nível da lúnula seguido de cerca de 12 pares de cílios; presença de discreta mancha castanha na veia r-m; ausência de pré-alar.

\section{Cyrtoneuropsis pallipes (Stein, 1918), comb.n.}

Figs 9-16

Síntipo macho (ZMHU): Reimoser/ Paraguay/ San Luis; Type [etiqueta vermelha]; Cyrtoneurina/ pallipes/sp.n. [etiqueta manuscrita];Zool. Mus. Berlin. Espécie em razoável estado de conservação, sem tarsos posteriores. Síntipo fêmea (ZMHU) Paraguay/ Fiebrig; Type [etiqueta vermelha]; pallipes [etiqueta manuscrita]; Zool. 


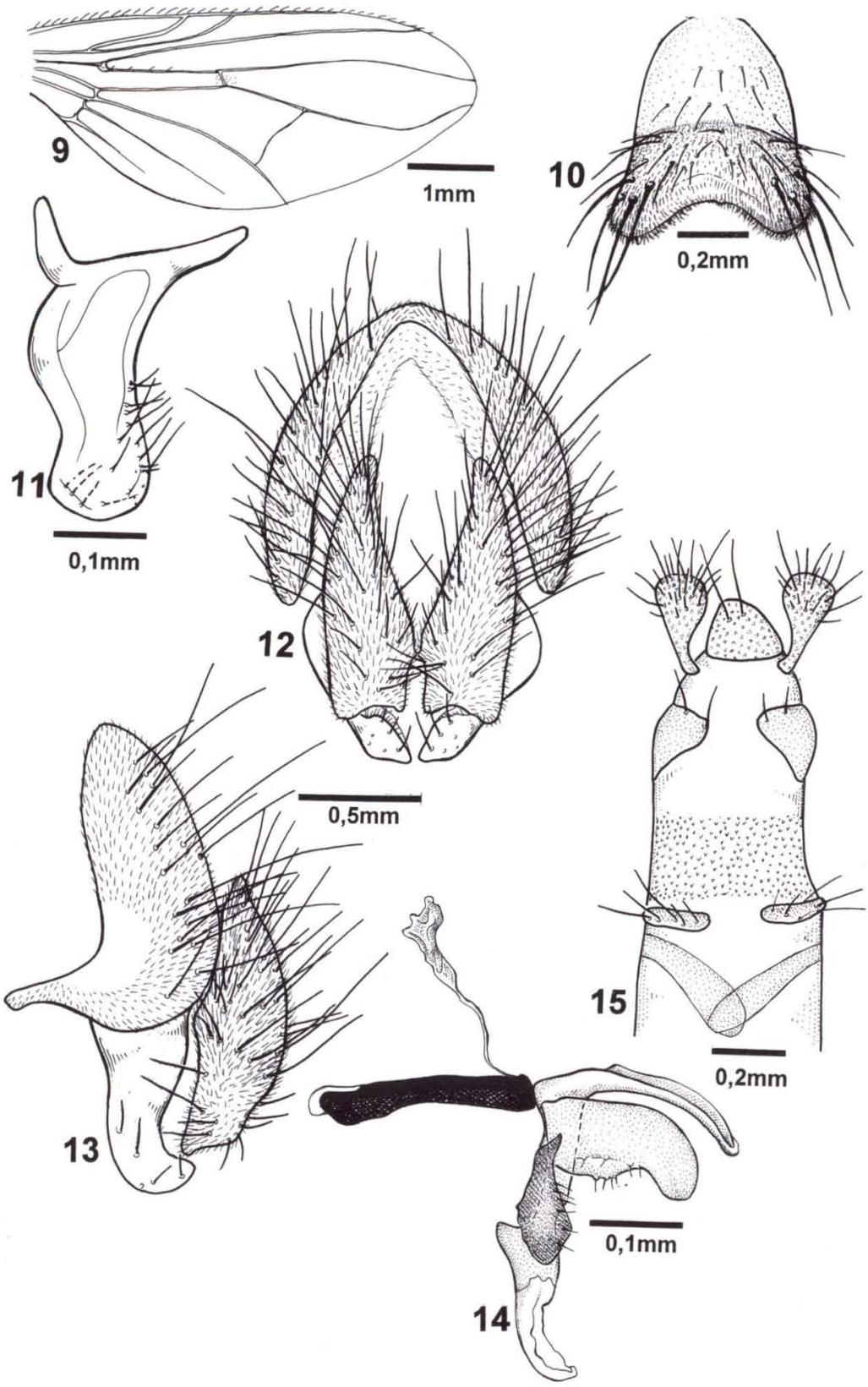

Figs 9-15. Cyrtoneuropsis pallipes. (9) Asa, vista dorsal; (10) quinto esternito, macho; (11) susrtilo; (12) placa cercal, vista dorsal; (13) placa cercal, vista lateral; (14) complexo fálico, vista lateral; (15) ovipositor, vista dorsal. 
Mus./ Berlin. Em bom estado de conservação. Abdômens dos síntipos dissecados e conservados em tubinho contendo glicerina.

O sintipo macho acima é designado aqui como lectótipo e o sintipo fềmea como paralectótipo.

Coloração. Tórax castanho-claro e abdômen com áreas amarelo-foscas e e polinosidade cinzenta. Parafaciália, faciália, lúnula e gena amarelas com polinosidade prateada; antena e metade basal da arista amarelas; probóscida castanho-clara e palpo amarelo. Asa com discreta mancha na r-m. Halter amarelo. Espiráculo castanho-claro sem mancha castanho-escura. Pernas amarelas.

Macho. Comprimento: corpo: 6,5mm; asa: 6,0mm.

Cabeça. Olhos com cílios esparsos e muito discretos de difícil observação, afastado por um espaço cerca de 12 vezes menor que a largura da cabeça no nível do ocelo anterior. Cerdas frontais em número de um par no nível da lúnula seguido de cerca de 12 pares de cílios (o último um pouco mais desenvolvido e retrovertido). Antena inserida no nível da metade do olho com o flagelo medindo cerca de 2,8 vezes o pedicelo. Arista em média com 28 cílios. Vibrissa forte, cerca do comprimento da arista. Palpo um pouco espatulado com cerca de quatro cílios longos na borda.

Tórax. Cerdas dorso-centrais 2:4; cerdas acrosticais 0:1; cerda pós-pronotal externa um pouco maior que a interna; cerda pré-alar ausente; cerda pós-alar posterior bem maior que a anterior; cerda intra pós-alar ausente. Notopleura com duas cerdas semelhantes entre si e com alguns cílios em toda extensão. Escutelo com dois pares de cerdas basais, um par de laterais, com os cílios látero-ventrais da base ao ápice. Prosterno ciliado. Duas cerdas proepisternais e duas cerdas pro-epimerais, as superiores maiores. Anepisterno com uma série de cinco cerdas na borda posterior. Anepímero com cílios longos e retos em toda extensão. Espiráculo posterior, sem cílios negros na borda inferior. Caliptra inferior medindo cerca de 1,7 vezes a superior. Asa com remígio na face dorsal ciliado, porção apical nua, veia $\mathrm{R}_{4+5}$, nas faces ventral e dorsal, ciliada logo após o nódulo e terminando antes da extremidade distal da asa; veia $\mathrm{M}_{1+2}$ próximo ao ápice com uma forte curvatura na direção da $\mathrm{R}_{4+5}$; dm-cu sinuosa (Fig. 9). Fêmur anterior nas faces anterior e ânter-ventral sem cerdas; faces póstero-ventral, posterior e póstero-dorsal com uma série de cerdas. Tíbia anterior na face póstero-ventral com uma cerda apical. Fêmur médiol na face ântero-ventral com a série de pêlos, mais longos na metade apical; face póstero-dorsal com três cerdas pré-apicais. Tíbia média nas faces ântero-ventral, póstero-ventral e ventral com uma, duas e uma cerdas apicais respectivamente. Fêmur posterior, na face ântero-ventral com três cerdas no terço apical. Tíbia posterior nas faces ântero-ventral e póstero-dorsal com três e duas cerdas pequenas no terço médio, respectivamente. Abdômen com quinto esternito com margem a arredondada e posterior com muitos cílios; superfície dorsal formando ângulo (Fig. 10).

Terminália. Surstilo sem ciliação e com muitas cerdas (Fig. 11). Placa cercal com margem anterior reta (Figs 12, 13). Edeago sem espinhos, gonópodo com seis cerdas (Fig. 14).

Fêmea. Comprimento do corpo: 6,5mm. Comprimento do asa: $6,0 \mathrm{~mm}$. 
Semelhante ao macho, diferindo no que se segue:

Olhos com bordas paralelas em direção ao vértice, afastados por um espaço 2,6 vezes menor que a largura da cabeça ao nível do ocelo anterior. Cerdas frontais em número de seis pares, intercaladas de um cílio.

Terminália. Ovipositor pouco telescopável; epiprocto grande e ciliado; hipoprocto com concavidade mediana margeada de cerdas (Figs 15, 16).

Registro geográfico. Paraguai.

Comentários. Para esta espécie, cabe os mesmos comentários feitos para $C$. brunnea. De acordo com a descrição original, esta espécie tem a quarta veia setulosa. SNYDER (1954: 460) faz o comentário de que, de que pode ter sido um engano tipográfico e que, na verdade, esta espécie deve ter a terceira veia setulosa. neste caso, esta espécie poderia ser um Neomuscina ou um "Cyrtoneurina" e, neste caso, próximo a $C$. brunnea, pois ambas tem a veia $\mathrm{M}_{1+2}$ como em Neomuscina. O exame do material estudado, confirma que é a terceira veia setulosa. Para segregação desta espécie com C. brunnea veja comentário em C. brunnea.

\section{Neomuscina scutellata (Johnson, 1919), comb.n.}

\section{Figs 17-21}

Holótipo macho: (MCZ) Holotype/ No.[etiqueta vermelha]; Liguanea Plain Jamaica/ Nov. Dec. 1911/ C. T. Brues; Type/ 7783 [etiqueta vermelha; número manuscrito]; Collection/ C. W. Johnson; C. scutellata/ John. [manuscrito de Johnson]. Em bom estado de conservação, faltando a perna II direita; perna III e asa direita em cápsula de gelatina. Abdômen dissecado e conservado em tubinho contendo glicerina.

Coloração. Tórax castanho com polinosidade cinzenta; abômen castanho. Parafaciália, faciália, lúnula e gena amarelas com polinosidade prateada; escapo e pedicelo amarelos; probóscida castanho-médio e palpo amarelo. Mesonoto anteriormente à sutura, dois terços apicais do escutelo e pleura com polinosidae mais intensa Úmero castanho. Halter com haste e cabeça castanhas. Espiráculo anterior castanho. Pernas castanho médio com articulações fêmur-tibiais amarelas.

Macho. Comprimento do corpo: 4,5mm. Comprimento da asa: 4,5mm.

Cabeça. Olhos afastados por um espaço cerca de 6,6 vezes menor que a largura da cabeça no nível do ocelo anterior. Cerdas frontais em número de dez pares iniciados no nível da lúnula e terminando no nível do ocelo anterior (o último ântero-vertido). Antena inserida acima do nível da metade do olho com flagelo medindo 2,4 vezes o pedicelo. Arista em média com 17 cílios. Vibrissa forte, menor que a arista. Palpo com cerca de quatro cílios curtos na borda.

Tórax. Cerdas dorso-centrais 2:4, as duas pós-suturais anteriores menores; cerdas acrosticais $0: 1$, uma cerda pré-sutural, uma intra-alar; cerda pré-alar um pouco maior que os pêlos de fundo; duas supra-alares, a anterior maior; duas pós-supra-alares, a posterior o dobro da anterior; cerdas umerais cerca do mesmo comprimento; cerda intra pós-alar ausente. Notopleura nua. Escutelo com um par de laterais cerca do comprimento do par apical; com cerca de dez cílios na metade basal abaixo do nível das cerdas escutelares, próximo à margem látero-ventral. 

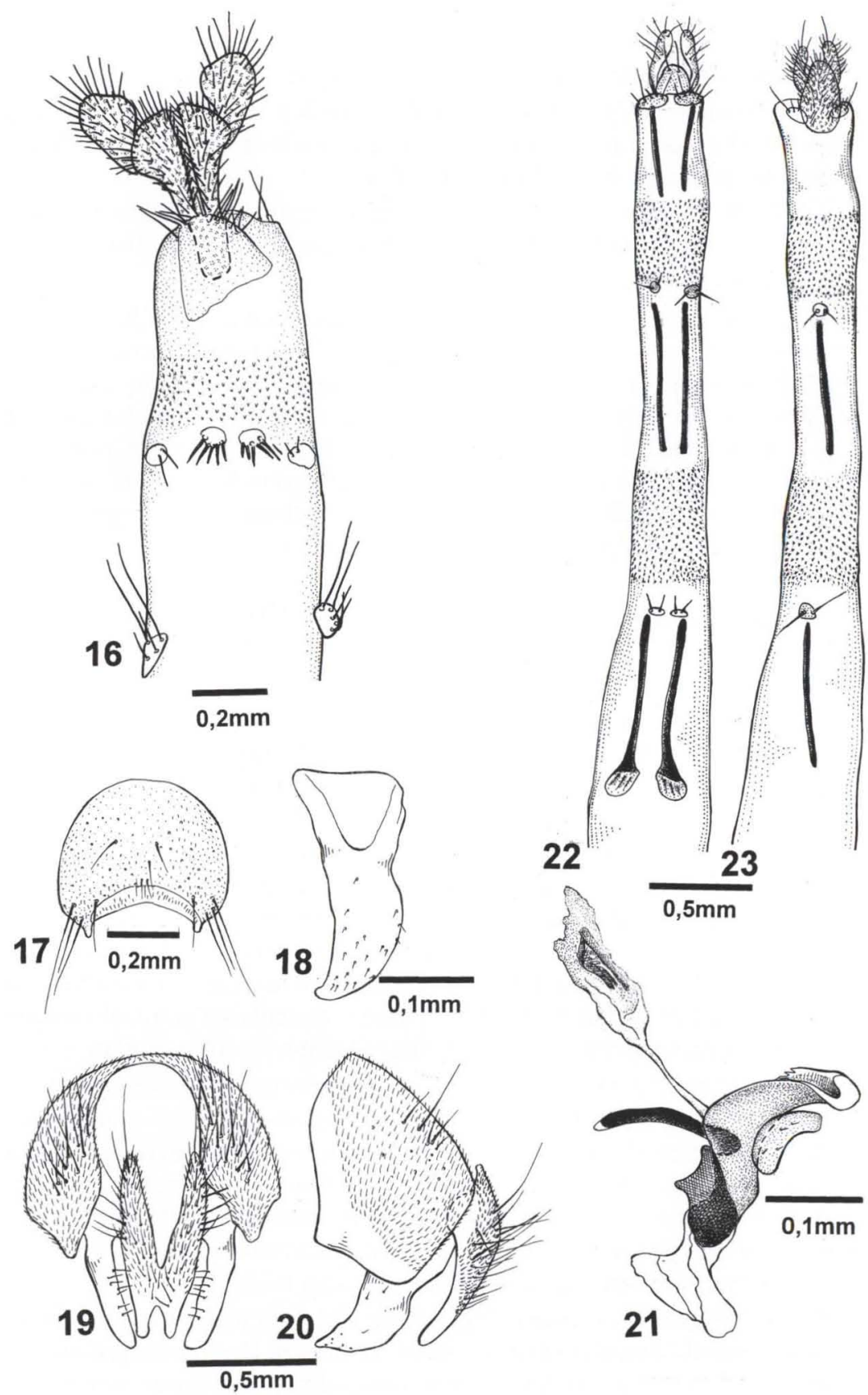

Figs 16-23. (16) Cyrtoneuropsis pallipes ovipositor, vista ventral; (17-21) Neomuscina scutellata: (17) quinto esternito; (18) surstilo; (19) placa cercal, vista dorsal; (20) placa cercal, vista lateral; (21) complexo fálico, vista lateral; (22-23) Cyrtoneurina alifusca: (22) ovipositor, vista dorsal; (23) ovipositor, vista ventral. 
Prosterno nu. Duas cerdas proepisternais e proepimerais acompanhadas de cílios, as cerdas superiores maiores. Anepisterno com cílios longos e com uma série de dez cerdas na borda posterior. Catepisternal póstero-superior maior que a pré-sutural. Anepímero com cílios curtos no disco. Catepímero nu. Espiráculo posterior sem cílios negros na borda inferior. Caliptra inferior medindo cerca de 1,6 vezes a superior. Asa, $\mathrm{R}_{4+5}$, faces dorsal e ventral ciliadas. $\mathrm{M}_{1+2}$ curva na direção da $\mathrm{R}_{4+5}$ e terminando no ápice da asa; dm-cu sinuosa. Tíbia anterior, na face ântero-ventral com uma cerda apical. Fêmur médio, na face dorsal com duas cerdas pré-apicais além das cerdas da face posterior. Tíbia média, na face posterior sem a cerda apical; face póstero-ventral com uma cerda apical e sem a cerda na face anterior. Fêmur posterior, face ântero-ventral com série de cerdas curtas e esparsas terminando nas duas cerdas no terço apical; face ventral com uma cerda curta no terço médio. Tíbia posterior, na face póstero-dorsal sem cerda; face dorsal com uma cerda pré-apical além da ântero-dorsal. Abdômen com quinto estrenito pequeno, com ápice arredondado e com poucas cerdas no disco (Fig. 17).

Terminália. Surstilo com cílios curtos, principalmente na metade apical (Fig. 18). Placa cercal com margem anterior aprofundada, em forma de "V" (Figs 19, 20). Edeago sem espinhos (Fig. 21).

Registro geográfico. Jamaica.

Comentários. Ainda não foi descrita a fêmea desta espécie. Confirmada a localização do holótipo no MCZC - Museum of Comparative Zoology, Cambridge, EUA, que CARVALHO et al. (1993) colocaram em dúvida. Esta espécie foi posicionada entre os Neomuscina pela seguinte combinação de caracteres: $\mathrm{R}_{1}$ nua, $\mathrm{R}_{4+5}$ com cílios apenas no início, após o nódulo, $\mathrm{M}_{1+2}$ curva em direção à $\mathrm{R}_{4+5}$, que termina antes da extremidade apical da asa; prosterno nu. Embora tenha sido considerada um Neomuscina, esta espécie apresenta um tamanho bastante menor do que a média das demais espécies deste gênero.

\section{Cyrtoneurina alifusca Couri, 1982}

Figs 22-23

Holótipo macho: (MNRJ) Holotipo [etiqueta vermelha]; Tinguá/ R. Janeiro/ Brasil [manuscrito]; RCS Shannon/ Collection; Serviço Febre/ Amarela/ M.E.S. Bras.; HOLOTIPO [etiqueta vermelha]; Cyrtoneurina alifusca/ Couri, 1982 [manuscrito de M. Couri]/M.S. Couri det. Estado geral bom; perna anterior e média direitas ausentes; abdômen dissecado e conservado em tubinho contendo glicerina.

Comentário. Esta espécie encontra-se bem descrita em CoURI (1982). Apresenta-se aqui apenas a ilustração do ovipositor (Figs 22-23), e confirma-se sua posição em Cyrtoneurina (sensu PAMPLONA 1999). Na chave de PAMPLONA (1999), C. alifusca, cujo macho é desconhecido, aproxima-se de C. crispaseta Snyder, 1954, e pode ser diferenciada desta última, pela presença no fêmur posterior, face ântero-ventral com duas a três cerdas e ausência de cílios dorsais secundários na arista e $C$. crispaseta uma cerda no fêmur posterior, face ântero-ventral e longos cílios dorsais secundários na arista. 
AGRADECIMENTOS. Agradecemos ao Dr. H. Schumann (ZMHU)) e ao Dr. H. Wendt e Dr. Michael S. Kelley (MCZC) pelo empréstimo do material e ao Sr. Luiz Antônio Alves da Costa (Museu Nacional) pela arte final das ilustrações. Agradecemos o apoio financeiro do CNPq (Proc: 300386-80 ZO; 524506/96-5) e da FAPERJ (Proc. E-26/170.694/99 e E-26/170.750/99).

\section{REFERÊNCIAS BIBLIOGRÁFICAS}

Carvalho, C.J.B. De; A. Pont; M.S. Couri \& D. Pamplona. 1993. A Catalogue of the Fanniidae and Muscidae of the Neotropical region. São Paulo, Sociedade Brasileira de Entomologia, 201p.

Couri, M.S. 1982. Adenda ao trabalho de Snyder (1954) sobre Cyrtoneurina Giglio-Tos, 1893 (Diptera, Muscidae, Cyrtoneurininae). Revta bras. Ent. 26 (1): 37-53.

PAmplonA, D.M. 1999. Nova caracterização de Cyrtoneurina Giglio-Tos, 1893 e descrição de Cyrtoneuropsis gen.n. (Diptera, Muscidae). Revta bras. Ent. 43 (1-2): 9-24

Pont, A.C. \& D.M. Pamplona (no prelo). A note on the genus Paracyrtoneurina Pamplona, 1999 (Diptera, Muscidae). Studia Dipterologica.

SNYDER, F.M. 1954. A revision of Cyrtoneurina Giglio-Tos, with notes on related genera (Diptera,

Muscidae). Bull. Amer. Mus. nat. Hist. 103: 417-464.

Recebido em 16.IX.1999; aceito em 13.XII.2000. 